\title{
Shear modulus of hydrate bearing calcareous sand-fines mixture
}

\author{
Litong Ji ${ }^{1}$, Abraham C.F. $\mathrm{Chiu}^{2 *}$, Lu $\mathrm{Ma}^{3}$ and Chao Jian ${ }^{3}$ \\ ${ }^{1}$ Nanjing TKA Technology, Nanjing, China \\ ${ }^{2}$ Department of Civil and Environmental Engineering, Shantou University, Shantou, China \\ ${ }^{3}$ Key Laboratory of Ministry of Education for Geomechanics and Embankment Engineering, Hohai University, Nanjing, China
}

\begin{abstract}
This article presents a laboratory study on the maximum shear modulus of a THF hydrate bearing calcareous sand (CS)-fines mixture. The maximum shear modulus was inferred from the shear wave velocity measured from the bender elements installed in a temperature-controlled triaxial apparatus. The specimen preparation procedures were specially designed to mimic the hydrate formation inside the internal pores of CS. A trial test was conducted to validate whether the shear wave velocity is a feasible parameter to monitor the formation and dissociation of hydrate in the CS-fines mixture. Based on the bender element test results, hydrate has a more profound effect than confining pressure on enhancing the maximum shear modulus of CS-fines mixture.
\end{abstract}

\section{Introduction}

Gas hydrate, an ice-like crystalline material formed by gas and water molecules, is considered as one of the potential future energy sources [1-2]. To model properly the gas production related geotechnical problems, such as subsea landslide and borehole instability, the mechanical properties of hydrate bearing sediment are required, e.g. shear modulus, coefficient of compressibility and angle of internal friction. Past studies on the mechanical behaviour of hydrate bearing soil have been mainly carried out in coarse-grained soils [3-4]. As some potential gas hydrate reservoirs have been found in fine-grained sediments, there is an increasing interest in studying the mechanical behaviour of hydrate bearing fine-grained soils [5-6]. The soil samples taken from the South China Sea have revealed that high hydrate saturation can be identified in the fine-grained sediment containing calcareous materials such as foraminifera [7]. It is postulated that the internal pores of calcareous materials facilitate the hydrate accumulation. As the morphology of hydrate-bearing sediment influences significantly its mechanical behaviour, it is interesting to understand how the hydrate affects the mechanical properties of the mixture of fines and calcareous materials. This paper presents a laboratory study on the maximum shear modulus of a hydrate bearing calcareous sand-fines mixture. Hydrate was formed in soil specimens installed in a temperaturecontrolled triaxial apparatus equipped with a pair of bender elements. A trial test is first presented to monitor the formation of hydrate inside the soil specimen in the triaxial apparatus using the shear wave velocity. Then, the effects of hydrate on the shear wave velocity and maximum shear modulus of the soil mixture are discussed based on the morphology of hydrate bearing soil mixture.

\section{Materials and methodology}

The tested soils were a calcareous sand (CS) and a nonplastic fines. The average grain size $\left(d_{50}\right)$ of CS is 0.75 $\mathrm{mm}$ and the maximum grain size of the fines is smaller than $75 \mu \mathrm{m}$. The soil mixture was formed by mixing the CS and the fines with a mass ratio of 1:4. $d_{50}$ of the soil mixture is $40 \mu \mathrm{m}$. Hydrate was formed using tetrahydrofuran (THF). At room temperature THF is miscible with water. THF was adopted in this study because it can form hydrate between $-10{ }^{\circ} \mathrm{C}$ and $0{ }^{\circ} \mathrm{C}$ under a relatively low pressure. Besides, the structure of THF hydrate is very similar to that of gas hydrate. Thus, it is anticipated that the behaviour of hydrate bearing soil formed by THF should be similar to that formed by natural gas hydrate.

To mimic the formation of hydrate inside the internal pores of the CS, the oven-dried samples of the CS was first soaked inside an aqueous solution formed by mixing THF and water with a volumetric ratio of 1:3.77. The purpose of the soaking procedure is to saturate the internal pores of the CS with the THF solution. This volumetric ratio is used to make sure all THF will form hydrate when it is subject to appropriate equilibrium pressure and temperature conditions. Thereafter the soaked CS was mixed with the dry fines thoroughly. The specimens were compacted directly on the base pedestal of the triaxial apparatus to the target relative dry density of $70 \%$.

The schematic layout of the temperature-controlled triaxial apparatus is shown in Fig. 1. The testing apparatus has a thermal controller which can regulate the temperature of the triaxial cell ranging from $-20{ }^{\circ} \mathrm{C}$ to 50 ${ }^{\circ} \mathrm{C}$. Dimethyl silicone oil is used in the temperature-

* Corresponding author: acf chiu@stu.edu.cn 
controlled oil bath and the triaxial cell. A set of bender element is installed at the top and bottom pedestals of the triaxial cell. The voltage signal of the bender elements is recorded by the oscilloscope. A typical bender element signal measurement using a single sinusoidal wave is shown in Fig. 2. The shear wave velocity $\left(v_{\mathrm{s}}\right)$ and maximum shear modulus $\left(G_{\max }\right)$ are calculated by the following equations:

$$
\begin{aligned}
& v_{\mathrm{s}}=\Delta L / \Delta t \\
& G_{\max }=\rho \mathrm{v}_{\mathrm{s}}^{2}
\end{aligned}
$$

where $\Delta L=$ the distance between bender elements, $\Delta t=$ the time difference between the emitted and received signals and $\rho=$ soil density. In the literature, there are several methods to determine $\Delta \mathrm{t}$ from the voltage signals [8-9]. In this study, $\Delta \mathrm{t}$ is considered as the time difference between the peak of emitted wave $\left(\mathrm{P}_{0}\right)$ and that of received wave $\left(\mathrm{P}_{1}\right)$ as shown in Fig. 2 . Besides, the frequency of the emitted wave also influences the bender element measurement. It is evident from Fig. 2 that the near field effect is quite significance at a low excitation frequency of $10 \mathrm{kHz}$. Thus a minimum excitation frequency of $25 \mathrm{kHz}$ was adopted for the sinusoidal wave in this study.

\section{Monitoring hydrate formation and dissociation}

A trial test was conducted to validate the formation and dissociation of hydrate in the specimen of CS-fines mixture using the thermal method. The compacted soil specimen was first subject to a confining pressure of 20 $\mathrm{kPa}$. After completion of consolidation, the temperature of the triaxial cell was reduced from the ambient temperature (around $13{ }^{\circ} \mathrm{C}$ ) to $-10{ }^{\circ} \mathrm{C}$ and then increased back to $5^{\circ} \mathrm{C}$. Figs. 3 to 5 show the measured shear wave velocity when the temperature of the triaxial cell is decreased from $13^{\circ} \mathrm{C}$ to $-10{ }^{\circ} \mathrm{C}$ in three stages. In the first stage, it is found that there is no significant change in the shear wave velocity when the temperature is decreased to $-2{ }^{\circ} \mathrm{C}$ (see Fig. 3). Thus, it is anticipated the stability condition of hydrate has not been reached and THF still exists in the liquid phase. In the second stage the temperature is further decreased and maintained at $-5{ }^{\circ} \mathrm{C}$ for at least two hours. The measured shear wave velocity increases substantially from $120 \mathrm{~m} / \mathrm{s}$ to around $600 \mathrm{~m} / \mathrm{s}$ as depicted in Fig. 4. It is postulated that the formation of solid phase hydrate fills up the pore space and also increases the contact area of the soil grains leading to an increase in the shear wave velocity. Thus, the stability conditions of hydrate have been reached at a temperature of $-5^{\circ} \mathrm{C}$ and a confining pressure of $20 \mathrm{kPa}$. In the third stage, the temperature is further decreased to $-10{ }^{\circ} \mathrm{C}$ and the shear wave velocity is approximately maintained at a constant value of $600 \mathrm{~m} / \mathrm{s}$ as shown in Fig. 5. After hydration formation the temperature is increased to $5^{\circ} \mathrm{C}$. It is evident from Fig. 6 that the shear wave velocity reduces from $600 \mathrm{~m} / \mathrm{s}$ to the initial value before hydrate formation (around $120 \mathrm{~m} / \mathrm{s}$ ). As the stability conditions of hydrate cannot be maintained, the hydrate dissociates and the occupied pores are filled up by the liquid phase of THF again leading to a reduction in the shear wave velocity.

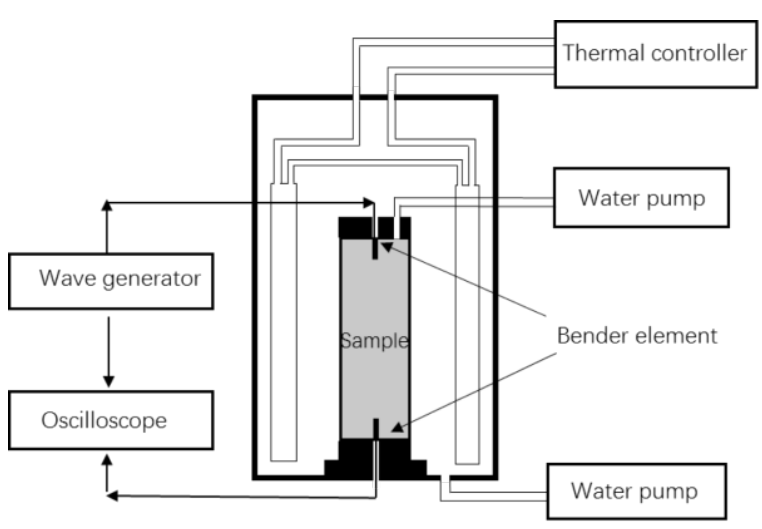

Fig. 1. Schematic layout of temperature-controlled triaxial apparatus

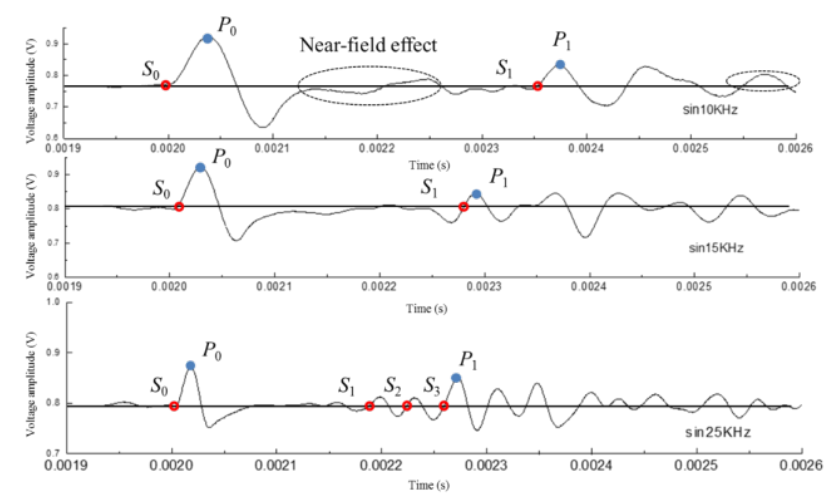

Fig. 2. Typical bender element measurement at different excitation frequencies using a single sinusoidal wave

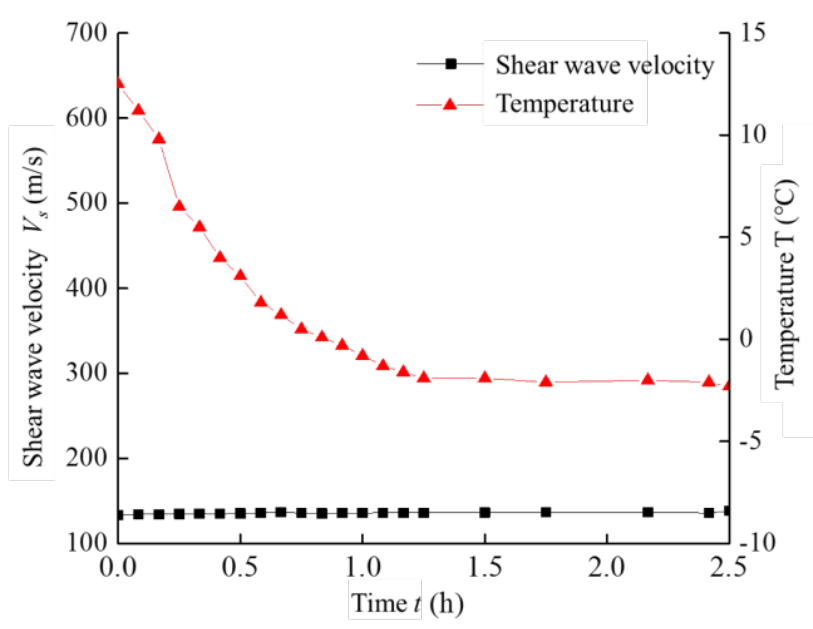

Fig. 3. Variation of shear wave velocity: temperature from 13 ${ }^{\circ} \mathrm{C}$ to $-2{ }^{\circ} \mathrm{C}$ 


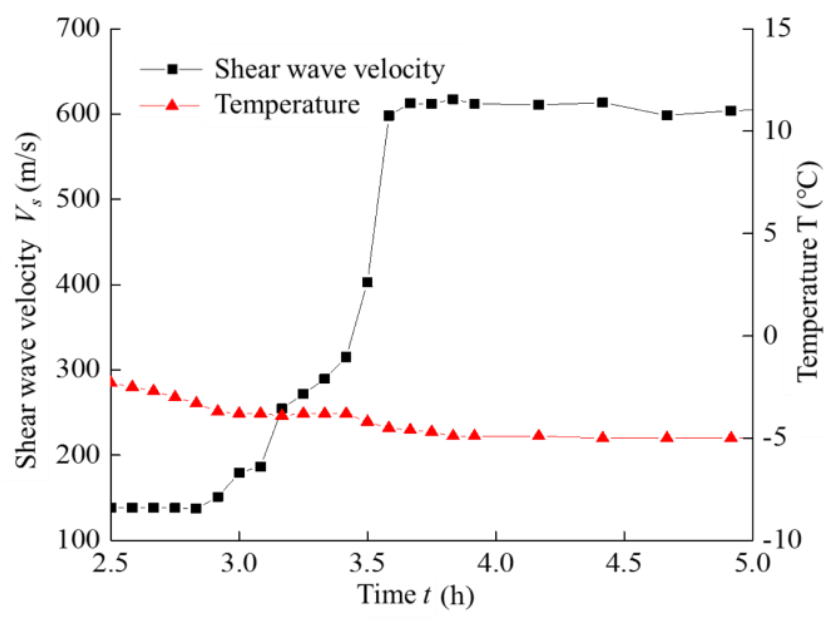

Fig. 4. Variation of shear wave velocity: temperature from -2 ${ }^{\circ} \mathrm{C}$ to $-5^{\circ} \mathrm{C}$

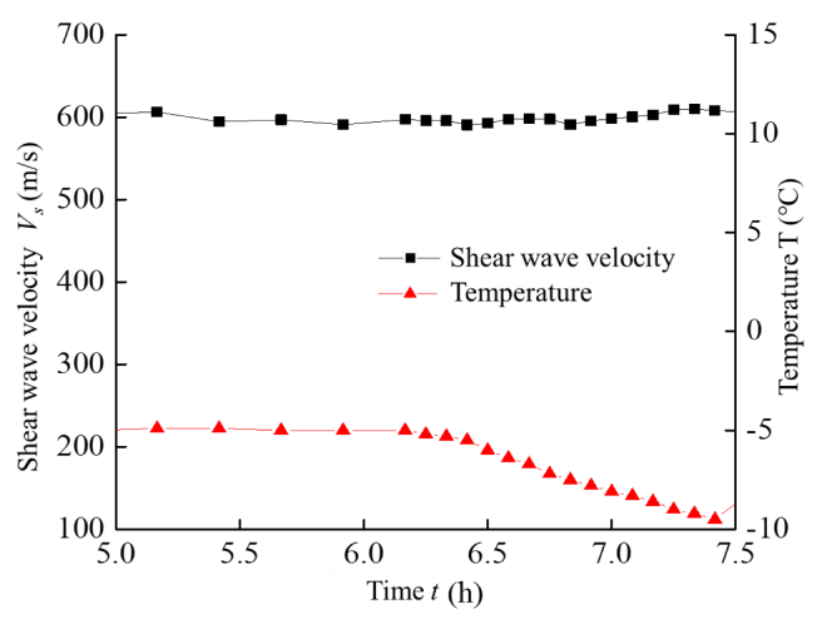

Fig. 5. Variation of shear wave velocity: temperature from -5 ${ }^{\circ} \mathrm{C}$ to $-10{ }^{\circ} \mathrm{C}$

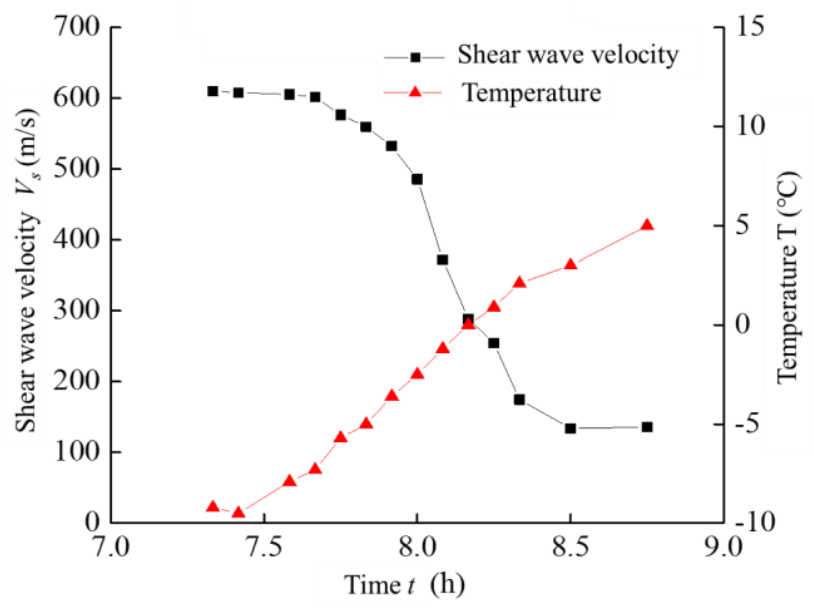

Fig. 6. Variation of shear wave velocity: temperature from -10 ${ }^{\circ} \mathrm{C}$ to $5^{\circ} \mathrm{C}$

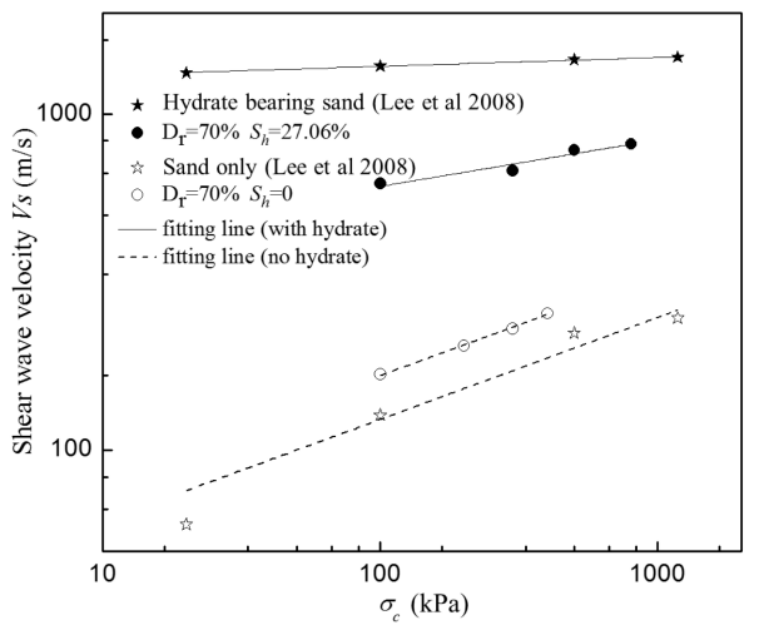

Fig. 7. Relationship of shear wave velocity and confining pressure for CS-fines mixture

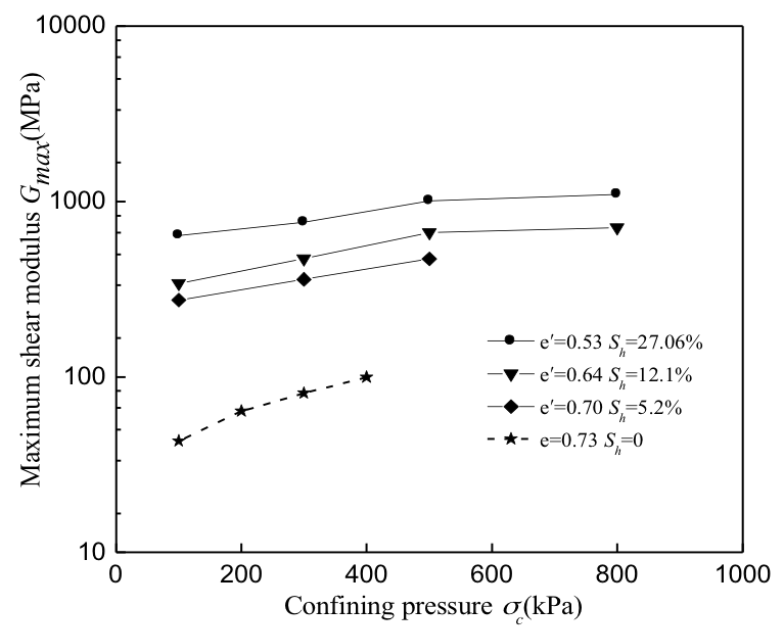

Fig. 8. Relationship of maximum shear modulus and confining pressure for CS-fines mixture

\section{Test results and discussion}

Fig. 7 shows the relationship of shear wave velocity and confining pressure for the CS-fines mixture. Two specimens were tested and both of them were prepared at an initial relative dry density of $70 \%$. Hydrate was formed in one specimen with a hydrate saturation of $27 \%$ and the other specimen is a control test without hydrate. It is shown from the figure that the hydrate bearing soil mixture exhibits a higher shear wave velocity than the one without hydrate for the range of confining pressure tested. The figure also depicts that the effect of confining pressure on the shear wave velocity is less profound for hydrate bearing specimen. The test results of this study are consistent with those of a hydrate bearing sand [10] shown in the figure. It should be noted that the hydrate saturation of the hydrate bearing sand is around 50\% while that of hydrate bearing CS-fines is around $27 \%$. As expected the hydrate bearing sand exhibits a higher shear wave velocity.

Fig. 8 depicts the relationship of maximum shear modulus and confining pressure for the CS-fines mixture. It should be noted that all specimens were prepared at the 
same initial relative dry density of $70 \%$ (or a void ratio of 0.73). After hydrate formation, some pores of the specimens were occupied by the solid phase hydrate and the actual void ratio (e') should be smaller than the initial void ratio of the soil mixture. For a hydrate saturation of $27 \%$, the void ratio decreases from 0.73 to 0.53 . The figure shows that the maximum shear modulus of all specimens increases with increasing confining pressure as expected. For the range of confining pressure studied, the maximum shear modulus increases with increasing hydrate saturation. Based on the possible hydrate morphology, hydrate formation has two mechanisms to enhance the stiffness of the soil mixture. First, decreasing the void ratio by filling up the internal pores of CS in the soil mixture and second, cementing at the inter-particle contacts.

\section{Conclusions}

A laboratory study is presented to study the effect of hydrate on the maximum shear modulus of a calcareous sand (CS)-fines mixture using bender element test. The specimen preparation procedures are specially designed to mimic the hydrate formation inside the internal pores of CS. A trial test is presented to monitor the hydrate formation and dissociation in the CS-fines mixture using the shear wave velocity. The bender element test results have revealed that hydrate has a more profound effect than confining pressure on enhancing the stiffness of CS-fines mixture. The maximum shear modulus of the soil mixture increases with increasing hydrate saturation. It is postulated that filling of internal pores of CS and cementing at the inter-particle contacts are the two possible mechanisms to enhance the stiffness of the soil mixture.

\section{References}

1. D. Grauls, Mar. \& Petrol. Geol. 18, 519-523 (2001)

2. N. Sultan, M. Voisset, T. Marsset, A.M. Vernant, E. Cauquil, J.L. Colliat, V. Curinier, Mar. Geol. 240, 235-255 (2007)

3. C.R.I. Clayton, J.A. Priest, E.V.L. Rees, Geotech. 60, 435-445 (2010)

4. M. Hyodo, J. Yoneda, N. Yoshimoto, Y. Nakata, Soils \& Found. 53, 299-314 (2013)

5. S. Kajiyama, M. Hyodo, Y. Nakata, N.Yoshimoto, Y. Wu, A. Kato, Soil \& Found. 57, 176-193 (2017).

6. L. Lei, J.C. Santamarina, J. Geophys. Res. Sol. Ear. 123, 2583-2596 (2018)

7. X. Wang, D.R. Hutchinson, S. Wu, S. Yang, Y. Guo, J. Geophys. Res. Sol. Ear. 116, B05102 (2011)

8. G. Viggiani, J.H. Atkinson, Geotech. 45, 149-154 (1995)

9. X.Q. Gu, J. Yang, M.S. Huang, G.Y. Gao, Soil \& Found. 55, 951-962 (2015)

10. J.Y. Lee, J.C. Santamarina, C. Ruppel, Mar. \& Petrol. Geol. 25, 884-895 (2008) 